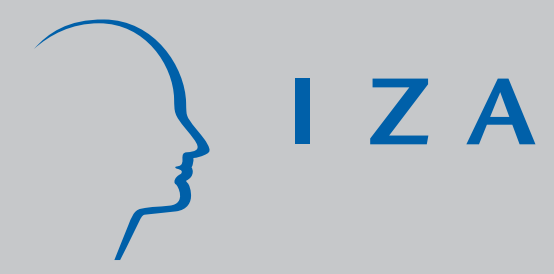

IZA DP No. 2391

Firm Size, Economic Situation and Influence Activities

Matthias Kräkel

October 2006 


\title{
Firm Size, Economic Situation and Influence Activities
}

\author{
Matthias Kräkel \\ University of Bonn \\ and IZA Bonn
}

\section{Discussion Paper No. 2391 \\ October 2006}

\author{
IZA \\ P.O. Box 7240 \\ 53072 Bonn \\ Germany \\ Phone: +49-228-3894-0 \\ Fax: +49-228-3894-180 \\ Email: iza@iza.org
}

\begin{abstract}
Any opinions expressed here are those of the author(s) and not those of the institute. Research disseminated by IZA may include views on policy, but the institute itself takes no institutional policy positions.

The Institute for the Study of Labor (IZA) in Bonn is a local and virtual international research center and a place of communication between science, politics and business. IZA is an independent nonprofit company supported by Deutsche Post World Net. The center is associated with the University of Bonn and offers a stimulating research environment through its research networks, research support, and visitors and doctoral programs. IZA engages in (i) original and internationally competitive research in all fields of labor economics, (ii) development of policy concepts, and (iii) dissemination of research results and concepts to the interested public.
\end{abstract}

IZA Discussion Papers often represent preliminary work and are circulated to encourage discussion. Citation of such a paper should account for its provisional character. A revised version may be available directly from the author. 
IZA Discussion Paper No. 2391

October 2006

\section{ABSTRACT \\ Firm Size, Economic Situation and Influence Activities ${ }^{*}$}

This paper discusses the optimal firm size in the presence of influence activities, and the level of individual rent-seeking dependent on the economic situation of the firm. Since firm size has a discouraging effect on the level of individual rent-seeking but also a quantity effect as the number of rent-seekers increases, the interplay of both effects determines whether the employer chooses an inefficiently small or large firm size. In the given setting, a bad economic situation leads to both a higher probability of a substantial loss and a reduction of productivity. The productivity effect and the two other effects together determine the optimal level of individual rent-seeking.

JEL Classification: D2, L2, M2

Keywords: economic situation, firm size, influence activities, politicking, rent-seeking

Corresponding author:

Matthias Kräkel

BWL II

University of Bonn

Adenauerallee 24-42

D-53113 Bonn

Germany

E-mail: m.kraekel@uni-bonn.de

\footnotetext{
* I would like to thank Oliver Gürtler for helpful comments. Financial support by the Deutsche Forschungsgemeinschaft (DFG), grants KR 2077/2-3 and SFB/TR 15, is gratefully acknowledged.
} 


\section{Introduction}

Organization members typically do not only use efficient actions in order to maximize their expected utility but also inefficient behavior which has been labeled politicking, internal rent-seeking or influence activities in the literature (Milgrom 1988, Milgrom and Roberts 1988). Such behavior leads to costs for the organization but is useful from an individual perspective for redistributing rents. There exist very different forms of influence activities. Several forms serve to manipulate performance measures. Often individuals try to show themselves in a more favorable light, ${ }^{1}$ but sometimes they want to hide their lights under a bushel. ${ }^{2}$ In other situations, division managers exert activities which influence the internal capital allocation. ${ }^{3}$ Employees may want to manipulate job-promotion decisions by bribing their superiors. ${ }^{4}$ Finally, organization members possibly try to influence relative performance pay or job-promotion tournaments by sabotaging their opponents. ${ }^{5}$ Altogether, Gibbons (2005) even speaks of an "elemental rent-seeking theory of the firm".

This paper discusses the relationship between firm size and influence activities and between the economic situation (of the firm) and influence activities. At first sight, we would expect that employers limit influence costs by reducing firm size and, therefore, the number of internal rent seekers (Holm-

\footnotetext{
${ }^{1}$ For example, there are problems of career concerns (Holmström 1982) and yes-men problems (Prendergast 1993, Ewerhart and Schmitz 2000).

${ }^{2}$ This does especially hold for the case of the ratchet effect (e.g. Baron and Besanko 1984).

${ }^{3}$ See Scharfstein and Stein (2000).

${ }^{4}$ See Fairburn and Malcomson (1994).

${ }^{5}$ See Lazear (1989), Konrad (2000).
} 
ström and Roberts 1998, p. 77). ${ }^{6}$ This aspect will be referred to as quantity effect in the paper. However, there may also exist a discouraging effect for individual rent seekers if the number of opponents becomes large, because a certain amount of influence activities has a lower relative weight. We will show that the employer optimally chooses an inefficiently large firm size if this discouraging effect dominates the quantity effect. Whether the discouraging or the quantity effect is dominant crucially depends on the given rent-seeking technology and the workers' cost functions.

The relationship between the economic situation of the firm and the intensity of individual rent-seeking seems to be ambiguous. On the one hand, it is possible that a bad situation implies the threat of layoffs which then leads to increased politicking of the workers who want to protect their jobs (Meyer, Milgrom and Roberts 1992, Bagwell and Zechner 1993). On the other hand, a bad economic situation may lead to less individual rent-seeking if workers expect to forfeit the returns of their influence activities because of the firm becoming insolvent (Schaefer 1998). In this paper, a bad situation or negative shock first has a negative productivity effect since the value of marginal product decreases. This effect reduces the optimal firm size and, therefore, the discouraging effect which finally results into more individual rent-seeking. However, in the model a negative shock does not only lead to reduced productivity but also to a higher probability that the employer bears a substantial loss. If the discouraging effect is very strong and the firm's substantial loss more important than the productivity effect the employer will prefer a large

\footnotetext{
${ }^{6}$ As an exception, Konrad (2000) shows that influence activities in form of sabotage are a special problem of small groups due to free riding of the sabotaging individuals.
} 
firm size in order to reduce individual and overall rent-seeking. Hence, in this situation a bad economic situation will be positively correlated with a low level of individual influence activities.

The setting discussed in this paper fundamentally differs from the ones used by Meyer, Milgrom and Roberts (1992), Bagwell and Zechner (1993), and Schaefer (1998) since we assume direct competition between the internal rent-seekers by explicitly modelling a rent-seeking contest. For this reason, the discouraging effect cannot appear in the three other papers. Hence, this paper adds to the existing literature by extending the discussion of firm size, firm crisis and influence activities on situations with strong internal competition between the workers who exert influence activities.

There are some other papers which analyze internal rent-seeking contests in organizations. As one of the first authors, Masten (1986) combines a formal rent-seeking model with the theory of the firm. He discusses a makeor-buy decision with possible bargaining and haggling between a seller and a buyer in the presence of quasi-rents. Müller and Wärneryd (2001) emphasize the advantages of outside ownership in the presence of internal rentseeking. They use their approach to explain the coexistence of partnerships and stock corporations. Konrad (2004) shows that organizing rent-seeking conflicts within a hierarchy may imply lower overall rent seeking expenditures. Inderst, Müller and Wärneryd (2005) point out that a large number of hierarchy levels may be beneficial for limiting overall rent-seeking. Inderst, Müller and Wärneryd (2006) stress the benefits of a multi-divisional firm for reducing internal rent-seeking. In particular, their arguments can be applied 
to explain the replacement of the U-form with the M-form during the twentieth century. Kräkel (2006) shows that efficient and highly profitable firms may not be founded because of anticipated excessive rent-seeking that will follow foundation.

The paper is organized as follows. The next section introduces a formal model on influence activities between competing workers. Section 3 addresses the relationship of firm size and influence activities. Section 4 deals with the economic situation (of the firm) and influence activities. In Section 5, the implications of an endogenous discretionary budget and possible applications will be discussed. Section 6 concludes.

\section{The Model}

We consider a firm with a single employer $E$ and $N$ workers. All individuals are assumed to be risk neutral. Firm size $N$ is endogenous and optimally chosen by $E .^{7}$ By employing $N$ workers, $E$ realizes $\operatorname{gross}^{8}$ profits

$$
\pi(N)=\theta \cdot Y(N)-w \cdot N
$$

where the exogenous productivity parameter $\theta>0$ characterizes the economic situation of the firm, $Y(N)$ is strictly concave (with $Y^{\prime}(N)>0$ and $\left.Y^{\prime \prime}(N)<0\right)$ and describes the firm's production function, and $w>0$ stands for a worker's exogenously given wage rate which exactly covers a worker's

\footnotetext{
${ }^{7}$ Although $N$ is a positive integer, for simplicity $N$ is treated as a continuous variable.

${ }^{8}$ In the subsequent paragraph, it becomes clear why $\pi(N)$ denotes "gross" profits.
} 
effort costs. Moral hazard problems regarding the firm's production are completely excluded.

However, internal relationships are not completely covert by explicit contracts. There is a discretionary budget $B>0$ which is transferred from $E$ to the workers due to incomplete contracting inside the firm. For simplicity, $B$ is exogenously given. The distribution of $B$ among the $N$ workers is determined by the workers' choices of influence activities or internal rent-seeking intensities $a_{i}(i=1, \ldots, N)$. We follow the rent-seeking technology suggested by Skaperdas (1996) and assume that worker $i$ 's $(i=1, \ldots, N)$ share of $B$ is given by the contest success function

$$
s_{i}\left(a_{i}\right)=\frac{f\left(a_{i}\right)}{\sum_{j=1}^{N} f\left(a_{j}\right)}
$$

with $f(\cdot)$ as positive increasing and concave function which measures the impact of influence activities $a_{i}(i=1, \ldots, N) .{ }^{9}$ Choosing influence activities $a_{i}$ leads to direct and indirect $\operatorname{costs} c_{i}\left(a_{i}\right)=c\left(a_{i} ; N\right)$ for worker $i(i=1, \ldots, N)$ with $c(0 ; N)=0, \partial c / \partial a_{i}>0, \partial^{2} c / \partial a_{i}^{2}>0, \partial c / \partial N \geq 0$, and $\partial^{2} c / \partial a_{i} \partial N \geq 0$. Hence, a worker's cost function is strictly convex in the magnitude of influence activities and non-decreasing in firm size. In order to guarantee an interior solution at the contest stage, the Inada conditions $\left.\frac{\partial c}{\partial a_{i}}\right|_{a_{i}=0}=0$ and $\left.\frac{\partial c}{\partial a_{i}}\right|_{a_{i}=+\infty}=+\infty$ are assumed to hold. The function $c\left(a_{i} ; N\right)$ covers all direct costs of internal rent seeking (e.g. bribe-money, a worker's opportunity costs of exerting time consuming influence activities) as well as a worker's indirect costs (e.g. expected costs of being punished as internal rent seeker

\footnotetext{
${ }^{9}$ For an application to internal rent-seeking see Inderst, Müller and Wärneryd (2006).
} 
by $E$ and/or the co-workers, expected personal disadvantages due to damaging the firm when exerting $a_{i}$, for example expected income loss because of decreased internal career prospects due to a firm decline). Costs $c\left(a_{i} ; N\right)$ are assumed to be non-decreasing in firm size because the larger the number of co-workers the higher will be the probability of being accused of rent-seeking by at least one co-worker and/or the employer, the higher will be worker $i$ 's start-up costs for influencing individuals (e.g. $i$ first has to gain each individual's confidence), the more information worker $i$ has to acquire about whom and how to influence, and the larger will be the co-workers' overall resistance against worker $i$ 's influence activities, for example.

It is assumed that the firm gets into trouble with probability $p\left(\sum_{i=1}^{N} a_{i}-\alpha \theta\right)$ where $p^{\prime}(\cdot)>0, p^{\prime \prime}(\cdot)>0$, and $\alpha>0$. If such crisis occurs the firm will realize a monetary loss $L>0 .{ }^{10}$ The probability of a crisis, $p\left(\sum_{i=1}^{N} a_{i}-\alpha \theta\right)$, increases in the total amount of counterproductive influence activities but decreases in the productivity parameter $\theta$. In other words, if the firm is in a really good situation, a given amount of internal rent-seeking will only lead to a rather small probability of a firm crisis, depending on the weighting factor $\alpha$.

\footnotetext{
${ }^{10}$ Note that worker $i$ 's disadvantages of a firm crisis resulting from influence activities are incorporated in the worker's objective function via $c_{i}\left(a_{i}\right)=c\left(a_{i} ; N\right)$.
} 
The time-schedule of the game is as follows.

\begin{tabular}{ccccc}
1 & 2 & 3 & 4 & 5 \\
\hline Nature & $E$ chooses & production & worker $i$ exerts & payments \\
chooses $\theta$ & firm size $N$ & takes place & $a_{i}(i=1, \ldots, N)$ &
\end{tabular}

First, nature chooses the economic situation of the firm, $\theta$, which becomes publicly observable. Then, employer $E$ hires $N$ workers depending on the economic situation and the anticipated worker behavior. Firm size $N$ determines firm output $Y(N)$ and, therefore, gross profits $\pi(N)$. Fourth, each worker $i$ chooses his optimal level of influence activities, $a_{i}$. Finally, each individual gets his payoff. Employer $E$ wants to maximize expected net profits

$$
E U_{E}(N)=\pi(N)-B-p\left(\sum_{i=1}^{N} a_{i}-\alpha \theta\right) \cdot L
$$

at the second stage, whereas worker $i(i=1, \ldots, N)$ maximizes

$$
E U_{W i}\left(a_{i}\right)=w+B \frac{f\left(a_{i}\right)}{\sum_{j=1}^{N} f\left(a_{j}\right)}-c\left(a_{i} ; N\right)
$$

at the fourth stage.

The next section will offer a solution of the game. In Section 4, the impact of the economic situation of the workers' equilibrium rent-seeking behavior is analyzed. 


\section{$3 \quad$ Firm Size and Influence Activities}

Before solving the game, the first-best solution is derived as a kind of benchmark solution. Under first-best conditions, we have no contractual problems so that individuals enter a forcing contract which maximizes welfare. Since from a welfare perspective influence activities only lead to costs, the firstbest level of influence activities simply is $a_{i}^{F B}=0=: a^{F B}(i=1, \ldots, N)$. First-best firm size, $N^{F B}$, then only maximizes profits $\pi(N)$ which implies

$$
\pi^{\prime}\left(N^{F B}\right)=0 \Leftrightarrow \theta \cdot Y^{\prime}\left(N^{F B}\right)=w .
$$

Hence, first-best firm size equalizes the value of marginal product and marginal labor costs.

Under the incomplete-contract setting described in Section 2, this solution cannot be implemented because individually rational rent-seeking is positive. In stage 4 of the game, worker $i$ 's optimal level of internal rent-seeking is characterized by the first-order condition ${ }^{11}$

$$
\frac{B}{\left(\sum_{j=1}^{N} f\left(a_{j}\right)\right)^{2}}=\frac{\partial c / \partial a_{i}}{f^{\prime}\left(a_{i}\right) \sum_{j \neq i} f\left(a_{j}\right)}
$$

Note that the first-order condition of any other worker $k \neq i$ yields

$$
\frac{B}{\left(\sum_{j=1}^{N} f\left(a_{j}\right)\right)^{2}}=\frac{\partial c / \partial a_{k}}{f^{\prime}\left(a_{k}\right) \sum_{j \neq k} f\left(a_{j}\right)}
$$

\footnotetext{
${ }^{11}$ The second-order condition is always satisfied since a worker's objective function is strictly concave.
} 
which, together with equation (6), leads to

$$
\frac{\partial c / \partial a_{i}}{f^{\prime}\left(a_{i}\right)} \sum_{j \neq k} f\left(a_{j}\right)=\frac{\partial c / \partial a_{k}}{f^{\prime}\left(a_{k}\right)} \sum_{j \neq i} f\left(a_{j}\right)
$$

Since both sides of the equation describe the same monotonically increasing function of $a_{i}$ or $a_{k}$, respectively, we have a symmetric equilibrium in which each worker chooses influence activities $a^{*}$ according to

$$
\frac{B(N-1)}{N^{2}}=H\left(a^{*} ; N\right) \Leftrightarrow a^{*}(N)=A\left(\frac{B(N-1)}{N^{2}} ; N\right)
$$

with $H(\cdot ; N):=\left[c^{\prime}\left(a^{*} ; N\right) \cdot f\left(a^{*}\right)\right] / f^{\prime}\left(a^{*}\right), c^{\prime}\left(a^{*} ; N\right):=\left.\frac{\partial c_{i}}{\partial a_{i}}\right|_{a_{i}=a^{*}}$, and $A(\cdot ; N)=$ $H^{-1}(\cdot ; N)$. Note that both $H(\cdot ; N)$ and $A(\cdot ; N)$ are monotonically increasing in the first argument. By implicit differentiation we obtain

$$
\frac{\partial a^{*}}{\partial N}=\frac{-\frac{B(N-2)}{N^{3}}-\frac{f\left(a^{*}\right)}{\partial H\left(a^{\prime} ;\right.} \frac{\partial^{2} c\left(a^{*} ; N\right)}{\partial a^{*} \partial N} / \partial a^{*}}{f^{*}}<0 .
$$

According to (8), an individual worker's equilibrium level of internal rentseeking is decreasing in firm size $N$. This effect can be labeled discouraging effect: The larger the number of co-workers, the lower will be the relative impact of individual rent-seeking which then leads to lower incentives for rent-seeking.

Now we can solve the second stage of the game where employer $E$ has to decide on the optimal firm size. $E$ maximizes

$$
E U_{E}(N)=\pi(N)-B-p\left(N \cdot a^{*}(N)-\alpha \theta\right) L .
$$


The first-order condition ${ }^{12}$ gives

$$
\pi^{\prime}(N)=p^{\prime}\left(N a^{*}(N)-\alpha \theta\right) L \cdot\left[a^{*}(N)+N \frac{\partial a^{*}}{\partial N}\right]
$$

Let $N^{*}$ denote the solution of equation (9). Then we have the following proposition:

Proposition $1 N^{*}>(<) N^{F B}$ iff $a^{*}\left(N^{*}\right)+N^{*} a^{* \prime}\left(N^{*}\right)<(>) 0$.

Proof. The gross profit function $\pi(N)$ is strictly concave with a unique maximum at $N^{F B}$ with $\pi^{\prime}\left(N^{F B}\right)=0$. If $a^{*}\left(N^{*}\right)+N^{*} a^{* \prime}\left(N^{*}\right)<(>) 0$, the solution $N^{*}$ will be to the right (left) of $N^{F B}$.

The result of Proposition 1 shows that the employer will choose an inefficiently large (small) firm size, if the expression in brackets in equation (9) is negative (positive). This expression describes the trade-off between two effects from marginally increasing $N$. The first term, $a^{*}\left(N^{*}\right)$, can be referred to as quantity effect: The more workers $E$ employs, the larger will be the number of individuals each exerting influence activities $a^{*}\left(N^{*}\right)$, respectively. This effect makes $E$ favor an inefficiently small firm size. The second term, $N^{*} a^{* \prime}\left(N^{*}\right)$, describes the discouraging effect mentioned above which always works into the opposite direction. Altogether, whether employer $E$ prefers a small or a large firm size depends on which of the two effects is dominant.

Of course, since $N$ is endogenous the employer's choice of firm size should be decisive for the dominance of the two effects. However, for certain spec-

\footnotetext{
${ }^{12}$ To guarantee an interior solution, we assume that the second-order conditon $E U_{E}^{\prime \prime}(N)=\pi^{\prime \prime}(N)-p^{\prime \prime}(\cdot)\left[\frac{\partial}{\partial N}\left(N a^{*}(N)\right)\right]^{2} L-p^{\prime}(\cdot)\left[2 \frac{\partial a^{*}}{\partial N}+N \frac{\partial^{2} a^{*}}{\partial N^{2}}\right] L<0$ is satisfied.
} 
ifications of the contest success function and the cost function the algebraic sign of the expression in brackets on the right-hand side of (9) is always positive or always negative:

Corollary 2 Let $f\left(a_{i}\right)=a_{i}$. (i) If $c\left(a_{i} ; N\right)=\frac{a_{i}^{2}}{2}$, then $N^{*}<N^{F B}$. (ii) If $c\left(a_{i} ; N\right)=\gamma(N) \frac{a_{i}^{2}}{2}$ with $\gamma(N) / N$ being strictly convex, then $N^{*}>N^{F B}$.

Proof. (i) In this scenario, we obtain $a^{*}(N)=\sqrt{B(N-1)} / N$, and $N a^{*}(N)=$ $\sqrt{B(N-1)}$ which is monotonically increasing in $N$. (ii) Now we have $N a^{*}(N)=\sqrt{\frac{B(N-1)}{\gamma(N)}}$ with

$$
\frac{\partial}{\partial N}\left(N a^{*}(N)\right)=\frac{B}{2} \sqrt{\frac{\gamma(N)}{B(N-1)}} \frac{\gamma(N)-(N-1) \gamma^{\prime}(N)}{\gamma(N)^{2}} .
$$

Since $\gamma(N) / N$ is strictly convex, the function $\gamma(N) / N^{2}$ is monotonically increasing, i.e.

$$
\frac{d}{d N}\left(\frac{\gamma(N)}{N^{2}}\right)=\frac{\gamma^{\prime}(N) N-2 \gamma(N)}{N^{3}}>0
$$

which implies that (10) and, hence, the term in brackets in (9) are always negative because $N \geq 2$.

The corollary deals with a rather simple rent-seeking technology as introduced by Tullock (1980). For a quadratic cost function which does not include firm size $N$, the quantity effect dominates the discouraging effect (result (i)). However, if firm size has an influence on individual rent-seeking costs, the discouraging effect may dominate the quantity effect even under the simple Tullock contest success function for all $N \geq 2$ (result (ii)). 


\section{Economic Situation and Influence Activi- ties}

The economic situation (of the firm) is characterized by the productivity parameter $\theta$. This parameter influences the value of marginal product and the firm's probability of a crisis. In order to analyze whether a good or a bad economic situation is positively correlated with a high individual level of internal rent-seeking, we first have to discuss the effect of a change of $\theta$ on the optimal firm size $N^{*}$. From Section 3 we know that $N^{*}$ is described by equation (9). Implicit differentiation yields

$$
\frac{\partial N^{*}}{\partial \theta}=\frac{Y^{\prime}\left(N^{*}\right)+p^{\prime \prime}\left(N^{*} a^{*}\left(N^{*}\right)-\alpha \theta\right) \alpha L\left[a^{*}\left(N^{*}\right)+N^{*} a^{* \prime}\left(N^{*}\right)\right]}{-E U_{E}^{\prime \prime}\left(N^{*}\right)} .
$$

Since $\partial a^{*} / \partial N<0$ we obtain the following result:

Proposition $3 d a^{*} / d \theta<(>) 0$ iff

$$
Y^{\prime}\left(N^{*}\right)+p^{\prime \prime}\left(N^{*} a^{*}\left(N^{*}\right)-\alpha \theta\right) \alpha L\left[a^{*}\left(N^{*}\right)+N^{*} a^{* \prime}\left(N^{*}\right)\right]>(<) 0 .
$$

The proposition shows that a high individual level of influence activities may be positively correlated either with a good or a bad economic situation. The intuition for this result is the following: First note that, in the given setting, the situation or productivity parameter $\theta$ directly influences the optimal firm size $N^{*}$ which then determines individual influence activities $a^{*}\left(N^{*}\right)$; due to the discouraging effect optimal rent-seeking $a^{*}\left(N^{*}\right)$ decreases in firm size. The numerator of the right-hand side of equation (11) consists 
of two terms. The first term, $Y^{\prime}(N)$, describes the marginal productivity which is always positive. Hence, according to this productivity effect the employer will increase the optimal firm size if $\theta$ becomes larger. The second term, $p^{\prime \prime}\left(N^{*} a^{*}\left(N^{*}\right)-\alpha \theta\right) \alpha L\left[a^{*}\left(N^{*}\right)+N^{*} a^{* \prime}\left(N^{*}\right)\right]$, can be shortly written as $-\partial^{2} p / \partial \theta \partial N^{*}$ which describes how the marginal probability of a crisis reacts to an increase of firm size. If the quantity effect dominates the discouraging effect, the term in brackets and, therefore, $-\partial^{2} p / \partial \theta \partial N^{*}$ will be positive. ${ }^{13}$ If the discouraging effect is dominant, the opposite will hold.

Altogether, we have to differentiate between two cases: (1) Given a dominance of the quantity effect, we unambiguously have $d a^{*} / d \theta<0$, i.e. individual rent-seeking increases when the economic situation of the firm becomes worse. The other way round, individual rent-seeking will decrease, if the economic situation of the firm becomes better. Note that in the initial situation the firm size is inefficiently small (see Proposition 1). If $\theta$ increases, first as a result of the productivity effect the employer will prefer to enlarge the firm towards the efficient size $N^{F B}$. Second, because of the dominant quantity effect the marginal probability of a crisis decreases in $N^{*}\left(\partial^{2} p / \partial \theta \partial N^{*}<0\right)$ which makes enlargement of the firm also attractive for employer $E$. Hence, the employer is unambiguously interested in increasing $N^{*}$ which leads to less internal rent-seeking by each worker.

(2) If the discouraging effect dominates the quantity effect, initially we have an inefficiently large firm size (see Proposition 1). Again, an increase of $\theta$ leads to the same productivity effect as in case (1) which would result

\footnotetext{
${ }^{13}$ Note that $p^{\prime \prime}(\cdot)>0$, by assumption.
} 
in an increase of $N^{*}$. However, the dominance of the discouraging effect over the quantity effect now works into the opposite direction; the marginal probability of a crisis increases in $N^{*}$ which favors a decline of firm size from the employer's viewpoint. If, in this situation, the discouraging effect is very strong and dominates both quantity and productivity effect, the employer will be interested in reducing firm size. The reduction of $N^{*}$ then results into a higher level of influence activities by each worker. If the discouraging effect does not dominate the other two effects, again the employer will prefer a larger firm size which implies less rent-seeking by each worker. Note that, if the discouraging effect dominates the quantity effect (i.e. the term in brackets is negative), then the larger the employer's loss in case of a crisis, $L$, and the larger the impact of the economic situation on the probability of a crisis, $\alpha$, the more likely will be a reduction of firm size. More generally, how the employer reacts to a productivity increase will depend on whether he is more concerned about the production process or about internal frictions such as influence activities.

\section{Discussion}

Up to now, the discretionary budget $B$ has been assumed to be exogenous. While this simplifying assumption makes the analysis quite concise it will not hold in general. In this section, the consequences of an endogenous $B$ will de discussed. Furthermore, I would like to discuss some applications of the theoretical results. 


\subsection{Endogenous Budget $B$}

Following Milgrom and Roberts (1992, pp. 573-574) we can assume that the discretionary budget increases in firm size:

$$
B=\beta(N) \text { with } \beta^{\prime}(N)>0 .
$$

Assumption (12) adds two effects to the former analysis. First, since $a^{*}$ is increasing in $B$ now there is an additional effect (incentive effect) when choosing $N$ which directly works against the discouraging effect. Regarding Proposition 1, an inefficiently small firm size becomes more attractive for the employer. If the incentive effect strictly dominates the original discouraging effect so that $\partial a^{*} / \partial N>0$, we will obtain the clear-cut result that the employer always chooses an inefficiently small firm size. Second, note that the employer's objective function (3) decreases in the discretionary budget $B$. According to (12) the transfer $B$ from $E$ to the workers increases in firm size. This distribution effect makes an inefficiently small firm size even more advantageous for employer $E$.

When reconsidering Proposition 3 and focusing on the incentive effect, we have to differentiate between two scenarios: (i) If the incentive effect weakens the discouraging effect but is not dominant, then $\partial a^{*} / \partial N<0$ will still hold. Because of the diminished discouraging effect it becomes more likely that the productivity effect and the quantity effect are dominant so that (11) is 
positive and we have

$$
\frac{d a^{*}}{d \theta}=\underbrace{\frac{\partial a^{*}}{\partial N^{*}} \frac{\partial N^{*}}{\partial \theta}}_{<0}<0 .
$$

In this scenario, a better economic situation alleviates the influence-activities problem. (ii) However, if the incentive effect is very strong and completely outweighs the discouraging effect, we will have $\partial a^{*} / \partial N>0$. In this case, each of the terms in expression $a^{*}\left(N^{*}\right)+N^{*} a^{* \prime}\left(N^{*}\right)$ in (11) is positive which implies

$$
\frac{d a^{*}}{d \theta}=\underbrace{\frac{\partial a^{*}}{\partial N^{*}} \frac{\partial N^{*}}{\partial \theta}}_{>0}>0 .
$$

In the initial situation, firm size is inefficiently small. An improved economic situation (i.e. an increase in $\theta$ ) has two implications. First, the productivity effect makes enlargement of $N$ beneficial for the employer. Second, the marginal probability of a crisis decreases in $N$ which also fosters increasing $N$. Altogether, a better economic situation unambiguously makes the employer increase firm size. This also happens in scenario (i). However, since in scenario (ii) the incentive effect is absolutely dominant, the main consequence is a strict increase of influence activities due to a higher discretionary budget following enlarged firm size.

As an alternative to assumption (12), we can assume that the discretionary budget depends on profits so that

$$
B=\gamma(\pi) \text { with } \gamma^{\prime}(\pi)>0
$$

This specification leads to similar consequences as assumption (12). Again, 
we would have a kind of incentive effect $\partial a^{*} / \partial \gamma \cdot \gamma^{\prime}(\pi)>0$ and a kind of distribution effect $\partial E U_{E} / \partial \gamma \cdot \gamma^{\prime}(\pi)<0$. Compared to the case of an exogenous $B$, now employer $E$ has less incentives to choose first-best firm size $N^{F B}$ which maximizes $\pi$. In particular, if the quantity effect is dominant, $E$ will prefer an inefficiently small firm size to deviate from maximum profits. Furthermore, if the incentive effect is quite strong, a better economic situation (i.e. an increase in $\theta$ ) will again lead to a higher level of influence activities since $a^{*}$ is increasing in $\pi$ which is increasing in $\theta$.

\subsection{Applications}

Finally, we can think about possible implications of the theoretical findings. In the given setting, employer $E$ optimally chooses firm size $N$ while bearing in mind the effects on influence activities being chosen by the workers at the next stage of the game. Moreover, the employer can directly affect the level of influence activities by his choice of firm size. For example, if the quantity effect is very strong and $E$ wants to reduce overall influence activities, he might choose divestitures such as spin-offs in order to reduce $N$.

However, the results have also shown that other motives (e.g. technological considerations) are more important for the employer when choosing firm size. In these situations, the theoretical findings can still help to shed some light on secondary effects like internal politicking. Consider, for example, the case of a merger. When employer $E$ acquires another firm in order to increase profits by generating synergy or a higher market concentration, this transaction has diverse implications on the intensity of influence activities. 
If the acquired firm is not completely closed, firm size $N$ will increase. On the one hand, increased firm size enlarges the number of internal rent seekers (quantity effect). On the other hand, an individual rent seeker is discouraged. Moreover, if the discretionary budget is endogenously determined by firm size $N$ or profits $\pi$ the incentive effect of Subsection 5.1 will apply, which results in higher individual incentives for internal politicking. In addition, the distribution effect of Subsection 5.1 will lead to another disadvantage for the employer. Altogether, if the amount of additional influence activities is quite large the employer might decide to forgo a merger that would be efficient in the absence of influence activities. ${ }^{14}$

Finally, the results can be applied to Williamson's "Chronic Puzzle" (Williamson 1985, pp. 132-135): He reconsiders the provoking question raised by Coase (1937) why there does not exist a single global corporation. This corporation should not act worse than the market because of selective intervention. In those instances where the corporation cannot do better than the market, it should simply replicate the market; but whenever market performance can be improved the corporation should do so. Hence, the puzzle remains why we do not observe one completely centralized corporation. There may exist several answers to this question; for example, Williamson's one is "that selective intervention is not feasible" (Williamson 1985, p. 135). However, the results on influence activities in firms offer a very promising argument for explaining why prohibitively high internal transaction costs naturally limit firm size. As the quantity effect and the incentive

\footnotetext{
${ }^{14}$ There are parallels to the "adverse selection" result of Kräkel (2006) in the context of founding organizations.
} 
effect should be of some importance in practice, economic activity should be split up into several firms of limited size for efficiency reasons.

\section{Conclusions}

When considering firm size and influence activities or internal rent-seeking, at first sight one might suppose that the employer should reduce firm size in order to cut down the intensity of internal politicking. However, the results have shown that, on the contrary, an increase of firm size will reduce influence activities, if individual rent seekers are discouraged by a large number of opponents. Furthermore, the paper shows that the relationship between a firm crisis and the level of influence activities is ambiguous. On the one hand, a bad economic situation makes production less productive. Therefore, the employer should adjust firm size downwards which leads to a smaller number of rent seekers but a higher intensity of individual rent-seeking since each individual becomes less discouraged. On the other hand, a bad economic situation leads to a higher probability that the employer will bear a substantial loss. If this potential loss is sufficiently large and, in addition, the discouraging effect sufficiently strong, the employer will optimally react by increasing firm size in order to make use of the discouraging effect.

The given analysis is based on the assumption that internal relations are only covered by incomplete contracts which leave room for politicking and haggling. As a consequence, we completely abstract from any contract solutions. However, from a principal-agent perspective one might think about 
further contractual aspects. For example, recall that we have assumed the absence of any incentive problems regarding production. Hence, workers' participation constraints should always be binding in the employer's optimum. But then reducing firm size would imply that a worker's individual share in the discretionary budget increases so that the employer should reduce the contractual wage rate in order to keep the participation constraint binding. Another issue would arise when introducing incentive problems into firm production. Besides the usual incentive problems due to limited liability or risk aversion, anticipated internal rent-seeking would further reduce incentives at the production stage because each individual will loose part of his fruits. Finally, collusion among the workers can be considered. Note that the workers are in a prisoners'-dilemma-like situation: In the symmetric equilibrium, each worker gets the same share in the discretionary rent. Hence, they can collectively gain by reducing rent-seeking activities to zero in order to save on effort costs. In a repeated-game context such collusion might be stable implying also a substantial benefit for the employer. Of course, in the presence of incentive problems in production, a collusion between the workers would have a rather ambivalent character. 


\section{References}

Bagwell, Laurie S., and Josef Zechner (1993): Influence Costs and Capital Structure, Journal of Finance 48, 975 -1008.

Baron, David P., and David Besanko (1984): Regulation and Information in a Continuing Relationship, Information Economics and Policy 1, $267-302$.

Coase, Ronald H. (1937): The Nature of the Firm, Economica 4, 386-405.

Ewerhart, Christian, and Patrick W. Schmitz (2000): Yes Men, Integrity, and the Optimal Design of Incentive Contracts, Journal of Economic Behavior and Organization 43, 115-125.

Fairburn, James A., and James M. Malcomson (1994): Rewarding Performance by Promotion to a Different Job, European Economic Review 38, 683-690.

Gibbons, Robert (2005): Four Formal(izable) Theories of the Firm?, Journal of Economic Behavior and Organization 58, 200-245.

Holmström, Bengt (1982): Managerial Incentive Problems - A Dynamic Perspective, Walross, B., Ed., Essays in Economics and Management in Honor of Lars Wahlbeck, Helsinki, 209-230.

Holmström, Bengt, and John Roberts (1998): The Boundaries of the Firm Revisited. Journal of Economics Perspectives 12:4, 73-94. 
Inderst, Roman, Holger M. Müller, and Karl Wärneryd (2005): Influence Costs and Hierarchy, Economics of Governance 6, 177-197.

Inderst, Roman, Holger M. Müller, and Karl Wärneryd (2006): Distributional Conflict in Organizations, European Economic Review (forthcoming).

Konrad, Kai A. (2000): Sabotage in Rent-Seeking Contests, Journal of Law, Economics and Organization 16, 155-165.

Konrad, Kai A. (2004): Bidding in Hierarchies, European Economic Review 48, 1301-1308.

Kräkel, Matthias (2006): On the "Adverse Selection" of Organizations, Discussion Paper, University of Bonn.

Lazear, Edward P. (1989): Pay Equality and Industrial Politics, Journal of Political Economy 97, 561-580.

Masten, Scott E. (1986): Institutional Choice and the Organization of Production: The Make-or-Buy Decision, Journal of Institutional and Theoretical Economics 142, 493-509.

Meyer, Margaret, Paul Milgrom, and John Roberts (1992): Organizational Prospects, Influence Costs, and Ownership Changes, Journal of Economics and Management Strategy 1, 9-15.

Milgrom, Paul R. (1988): Employment Contracts, Influences Activities, and Efficient Oganization Design, Journal of Political Economy 96, 42-60. 
Milgrom, Paul R., and John Roberts (1988): An Economic Approach to Influence Activities in Organizations, American Journal of Sociology 94, S154-S179.

Milgrom, Paul R., and John Roberts (1992): Economics, Organization and Management, Englewood Cliffs.

Müller, Holger M., and Karl Wärneryd (2001): Inside Versus Outside Ownership: A Political Theory of the Firm, RAND Journal of Economics 32, 527-541.

Prendergast, Canice J. (1993): A Theory of "Yes Men", American Economic Review 83, 757-770.

Schaefer, Scott (1998): Influence Costs, Structural Inertia, and Organizational Change, Journal of Economics and Management Strategy \%, $237-263$.

Scharfstein, David S., and Jeremy C. Stein (2000): The Dark Side of Internal Capital Markets: Divisional Rent-Seeking and Inefficient Investment, Journal of Finance 55, 2537-2564.

Skaperdas, Stergios (1996): Contest Success Functions, Economic Theory 7, 283-290.

Tullock, Gordon (1980): Efficient Rent Seeking, Buchanan, J.M., R.D. Tollison, and G. Tullock, Eds., Toward a Theory of the Rent-Seeking Society, College Station, 97-112. 
Williamson, Oliver E. (1985): The Economic Institutions of Capitalism, New York. 